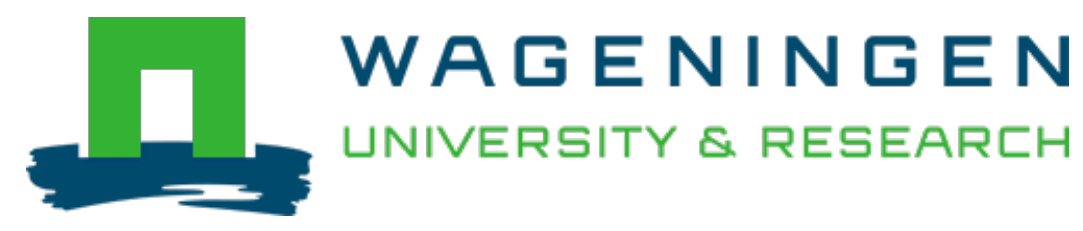

\title{
Perceived obstacles for business development : Construct development and the impact of farmers' personal values and personality profile in the Swedish agricultural context
}

Journal of Rural Studies

Hansson, Helena; Sok, Jaap

https://doi.org/10.1016/j.jrurstud.2020.12.004

This article is made publicly available in the institutional repository of Wageningen University and Research, under the terms of article $25 \mathrm{fa}$ of the Dutch Copyright Act, also known as the Amendment Taverne. This has been done with explicit consent by the author.

Article 25 fa states that the author of a short scientific work funded either wholly or partially by Dutch public funds is entitled to make that work publicly available for no consideration following a reasonable period of time after the work was first published, provided that clear reference is made to the source of the first publication of the work.

This publication is distributed under The Association of Universities in the Netherlands (VSNU) 'Article $25 \mathrm{fa}$ implementation' project. In this project research outputs of researchers employed by Dutch Universities that comply with the legal requirements of Article 25fa of the Dutch Copyright Act are distributed online and free of cost or other barriers in institutional repositories. Research outputs are distributed six months after their first online publication in the original published version and with proper attribution to the source of the original publication.

You are permitted to download and use the publication for personal purposes. All rights remain with the author(s) and / or copyright owner(s) of this work. Any use of the publication or parts of it other than authorised under article $25 \mathrm{fa}$ of the Dutch Copyright act is prohibited. Wageningen University \& Research and the author(s) of this publication shall not be held responsible or liable for any damages resulting from your (re)use of this publication.

For questions regarding the public availability of this article please contact openscience.library@wur.nl 


\title{
Perceived obstacles for business development: Construct development and the impact of farmers' personal values and personality profile in the Swedish agricultural context
}

\author{
Helena Hansson ${ }^{\mathrm{a}, *}$, Jaap Sok ${ }^{\mathrm{b}}$ \\ ${ }^{a}$ Swedish University of Agricultural Sciences, Department of Economics, P.O. Box 7013, SE-75007, Uppsala, Sweden \\ ${ }^{\mathrm{b}}$ Wageningen University and Research, Department of Social Sciences, Division of Business Economics, P.O. Box 8130, 6700EW, Wageningen, the Netherlands
}

\section{A R T I C L E I N F O}

\section{Keywords:}

Farms

Individual differences

Perceived obstacles for business development

Sweden

\begin{abstract}
A B S T R A C T
The objective of this study was twofold: first, to assess the empirical content and structure of farmers' perceptions of obstacles for business development, and second, to explore how individual differences between farmers relate to these perceptions. The study is based on survey data collected from Swedish agriculture in 2018. We estimated a latent variable representing farmers' perception of obstacles for business development using a MIMIC model approach and included measures of personal values and personality traits to the model to take into account individual differences. The findings suggest that the surveyed farmers' perceptions of obstacles for the development of their businesses centre around the following areas: access to financial resources; farm layout (in terms of physical layout of the farmyard and fields) and geographical location; consumer demand; available resources and options for farm succession. Only individual differences in terms of personality traits that relate to entrepreneurship (extraversion and openness), could be related to the perceived obstacles. The findings are useful for prioritising agricultural policy and for the design of extension and advisory services aimed at assisting farmers to develop their business - particularly in Sweden but also in regions similar to Sweden. Furthermore, the approach developed here is informative for other policy makers and advisory services interested in prioritising efforts to better support farmers' business development.
\end{abstract}

\section{Introduction}

Sustainability and resilience of the agricultural sector is highly prioritised by policy makers in Europe and measures to improve the market potential of farms are high up on the policy agenda (European Commission, 2017). In particular, measures to stimulate investment in farms, with the aim of promoting restructuring, innovation, diversification, and farmers' uptake of new technologies and digital solutions, are among the prioritised areas in the common agricultural policy (CAP) (European Commission, 2017) and echoed in individual member states' policy documents. A resilient agricultural sector is viewed as a means not only to maintain high quality and affordable food for European consumers but also to maintain the public good aspects of agricultural production, such as ecosystem services, rural landscape production and reduced environmental impact. The agricultural sector is also an important element for growth and development in rural areas.

Implicit in much agricultural policy is the idea that there are certain obstacles for farmers when developing their businesses in accordance with changes in the surrounding society. Policy can, at least partly, function to mitigate or diminish the impact of these obstacles, leading to a more resilient and sustainable agricultural sector. Previous literature has highlighted that agricultural policy design must build on in-depth understandings of the factors that underlie and determine farmer behaviour (Pietola and Lansink, 2001; Viaggi et al., 2011). In this spirit, previous studies have investigated factors that impact investment reactions in relation to the decoupling of the CAP (Viaggi et al., 2011), the role of farm advisors in policy uptake (Vrain and Lovett, 2016) and the interactions between agricultural policy and various behavioural factors in preventing exiting behaviour among young farmers (May et al., 2019). The role of the farmers' decision making context in assessing or evaluating policy measures is also emphasised by Huber et al. (2018) in their review on how decision making is represented in agricultural agent-based models in Europe.

In this context, we argue that policy design must depart from a clear

\footnotetext{
* Corresponding author.

E-mail address: Helena.Hansson@slu.se (H. Hansson).
} 
understanding of which factors farmers think prevent them from developing their businesses in the way that they prefer. Farmers are driven by pecuniary considerations or by a combination of pecuniary and non-pecuniary values such as social values or values of lifestyle type (Ferguson and Hansson, 2013; Gasson, 1973; Howley, 2015; Willock et al., 1999). Indeed, non-financial benefits in farming can explain farmer behaviour over a range of different activities such as decisions to increase production, engaging in farm diversification and plans to stay in farming (Howley, 2015). Focusing on the obstacles farmers experience in developing their businesses allows for a range of different financial and non-financial benefits to dominate farmers' behaviours.

Knowing which factors farmers believe prevent them from developing their businesses in their preferred way would be useful for design of agricultural policy, but also for the extension and advisory services helping to develop individual farm businesses. However, it is not always clear which factors these are and how they relate to each other. Accordingly, in this paper, we assess farmers' perceptions of obstacles for business development (POBD) by investigating the empirical content and structure of this construct among a sample of Swedish farmers. This is our first objective. Knowing the structure, including the dimensions of the perceived obstacles and their relative contribution, gives important insight into which areas of policy and advisory services to prioritise by suggesting which obstacles farmers consider the most pressing. Furthermore, we explore how individual differences between farmers relate to their most important POBD. This is our second objective. We focus on personal values and the personality profile, both of which have been found to impact individuals' behaviours in relation to business activities. For instance, personal values have been found to be related to entrepreneurial activities (Fayolle et al., 2014), and to the choice of strategic orientation of a business (Kotey and Meredith, 1997). Personality has been found to relate to individual's occupational status (Brandstätter, 2011; Zhao and Seibert, 2006), willingness to be self-employed (Brandstätter, 2011; Zhao et al., 2010) and the success of entrepreneurial activities (Brandstätter, 2011; Leutner et al., 2014; Zhao et al., 2010).

A review of previous literature related to obstacles for business development indicates that surprisingly few studies have focused on this area and that the current research is scattered over a wide set of empirical areas. Outside of the farm-focused literature, van Geenhuizen and Soetanto (2009) investigated key obstacles for growth among academic spin-offs. Phillipson et al. (2018) investigated the differences in obstacles encountered between urban and rural SMEs. Long et al. (2016) analysed obstacles for technology adoption and diffusion of climate-smart agriculture among supply chain actors in four European countries. However, to the best of our knowledge, no previous study has focused explicitly on the empirical content and structure of farmers' POBD or on behavioural variables that relate to those perceptions. Within the farm-focused literature, there has instead been much interest in determinants for farmers' uptake of specific strategic orientations, such as farm diversification (Barbieri and Mahoney, 2009; Barnes et al., 2015), specific technologies (Adrian et al., 2005; Reichardt et al., 2009) or production methods like organic agriculture (Dessart et al., 2019; Hansson et al., 2019). However, from this literature we cannot come to any conclusions on farmers' POBD or how they are formed, something that would be helpful for efficient agricultural and rural policy design.

Our analysis yields valuable insights into i) farmers' POBD and ii) how farmers' personality and personal values relate to these perceptions. From a policy perspective, this yields an important insight into which agricultural and rural policy areas should be prioritised in Sweden and in regions similar to Sweden to encourage farm business development by mitigating obstacles for business development. Furthermore, the approach developed here is informative for understanding how POBD of farmers in other regions can be assessed and used to inform efficient agricultural and rural policy.

This paper now continues by developing a conceptual background and presenting material and methods in Section 2. Results are presented in Section 3. Section 4 ends the paper by presenting discussion and conclusions.

\section{Research approach}

\subsection{Developing a conceptual background}

\subsubsection{Perceived obstacles for business development (POBD): previous research and hypothesised content}

As a first objective, we investigated the empirical content and structure of farmers' POBD. We specifically focused on obstacles for business development, which should be understood as a wide and allencompassing construct, instead of more narrow constructs such as growth or profit maximisation. By focusing on the obstacles farmers' perceive in developing their farms in their preferred way, we allow for multiple goals among farmers. Following this, POBD is likely multidimensional.

Based on previous literature and qualitative assessments of the POBD construct, we hypothesised the content of the construct to centre on the following areas: financial resources, competitors, business partners, current and prospective profitability in farm operations, access to knowledge and skills, institutional settings, geographical setting and farm layout (in terms of physical layout of the farmyard and fields). Kollmann et al. (2017), identified categories of obstacles for business development as being related to financial resources, competitors and business partners. We used this set of obstacles categories to develop a preliminary understanding of the construct. Following this, we compared with obstacles identified through a process of qualitative data collection based on interviews with a 51 farmers (Swedish University of Agricultural Sciences, 2018). In particular, that study used Means-End Chain theory (Gutman, 1982; Reynolds and Gutman, 1988) and the associated laddering interview technique (Olson, 1989; Reynolds and Gutman, 1988) to map obstacles for business development as identified by farmers, consequences of these obstacles and why these consequences were important to the farmers. Additional obstacles related to current and prospective profitability in farm operations and access to knowledge and skills could be identified and added through this step. Finally, the set of obstacles was scrutinised by a reference group consisting of experts in the business development of agricultural and forestry firms. Through this procedure the set of possible obstacles was complemented with possible obstacles originating from the institutional settings, geographical setting and farm layout (in terms of physical layout of the farmyard and fields).

\subsubsection{Individual differences: personal values and personality}

As a second objective, we investigated how farmers' POBD relate to individual differences in terms of personal values and personality, or to a combination of these two. Personal values and personality describe conceptually different aspects of an individual and, in empirical comparisons, they have been found to represent related but distinct constructs (Parks-Leduc et al., 2015).

Personal values represent the standards that people use to evaluate and guide their behaviours (Bardi and Schwartz, 2003; Rohan, 2000). Schwartz (1992, 2012) identified personal values as beliefs (related to desired goals), trans-situational (functioning as standards that guide action or evaluations), and ordered according to their importance. Ten universal personal value dimensions have been found, which exist along a motivational continuum (Bardi and Schwartz, 2003; Schwartz, 1992) and can be in motivational conflict with each other. Their universal existence has been confirmed in research using large cross-cultural datasets (Schwartz and Boehnke, 2004). The ten personal value dimensions can be grouped into a subset of four summarising categories: self-transcendence (which relates to universalism and benevolence), self-enhancement (which relates to hedonism, achievement and power), openness to change (which relates to hedonism, stimulation and self-direction) and finally conservation (which relates to conformity, 
tradition and security) (Schwartz, 2012).

Personality traits have been described as related to the biophysiological response system; innate; resistant to influences by the social context in which the individual exists; and stable over the individual's adult life (Olver and Mooradian, 2003). In empirical research attempting to characterise individuals' personality traits, the Big Five model (John et al., 1991, 2008) is often used. The Big Five model distinguishes five personality traits: neuroticism, openness to experience, extraversion, agreeableness and conscientiousness. These are thought to capture much of human personality.

\subsubsection{Relationship between personal values and personality and perceptions of obstacles}

In this study we link personal values and personality to farmers' perceptions of obstacles for business development. It is plausible to assume that perceptions of obstacles are guided by what the farmers would like to achieve by running the business. Informed by the literature that acknowledges farmers to be guided by pecuniary as well as nonpecuniary benefits in their business activities (Ferguson and Hansson, 2013; Gasson, 1973; Howley, 2015), we therefore posit that farmers act to maximise their utility from both pecuniary and non-pecuniary benefits from running the farm, rather than simply to maximise profits and that these attempts determine their evaluation of obstacles for business development. This thus means that farmers' perceptions of obstacles for business development are determined from their ambitions to maximise their utility from their farm; this utility is derived from any pecuniary and non-pecuniary benefit recognised by the farmer. Because personal values represent desirable goals of individuals and function as their guiding principles (Roccas et al., 2002; Schwartz, 1992, 2012), we assume that they act in guiding farmers in what they would like to achieve from their business; thus their pecuniary and non-pecuniary aspirations from running a farm business. We therefore expect the extent to which individual farmers' are guided by certain personal values to relate to the intensity with which they perceive obstacles for business development.

Moreover, because personality traits record the intensity with which an individual undertakes an action (Roccas et al., 2002) and how they respond to the environment (Olver and Mooradian, 2003), we assume that farmers with different types of personality will consider different types of pecuniary and non-pecuniary goals in their farm business and therefore in their perceptions of obstacles for business development. We therefore expect that the extent to which individual farmers show specific personality traits to relate to how they respond to the environment and thereby to the intensity with which they perceive obstacles for business development.

\subsection{Instruments used}

\subsubsection{Perceptions of obstacles to business development}

In line with the conceptual background introduced above, the content of the POBD was hypothesised to consist of obstacles in the following areas: financial resources, competitors, business partners, current and prospective profitability in farm operations, access to knowledge and skills, institutional settings, geographical setting and farm layout (in terms of physical layout of the farmyard and fields). Farmers' were asked to rate a corresponding set of obstacles (see the result section) on a scale from 1 to 9 , where $1=$ not at all an obstacle, 9 $=$ very much an obstacle, to indicate the extent to which they considered each suggested obstacle to impede their possibilities to develop their business the way they would like to. This way of posing these questions allowed the farmers to evaluate each obstacle in relation to their own, individual goal-function, as they may be driven by pecuniary as well as non-pecuniary benefits (Ferguson and Hansson, 2013; Howley, 2015).

\subsubsection{Individual differences: personal values and personality}

To assess individual differences between farmers in terms of personal values and personality, the validated scales described in the literature were used. In particular, farmers' personal values were assessed using the typology developed by Schwartz (1992). To avoid burdening the farmers with a very lengthy questionnaire, we opted for the short version of the Schwartz personality scale (Lindeman and Verkasalo, 2005a) and used their recommended linear equations to calculate scores on two main value dimensions: self-transcendence (S-T) and conservation (Cn). The Big Five personality inventory (John et al., 1991, 2008) was used to assess farmers' personality traits in five established dimensions. Again, to avoid burdening the farmers with a very lengthy questionnaire, we opted for the short 11-item version of the Big Five personality scale (Rammstedt and John, 2007).

\subsection{Data}

The data for this study was collected from an online survey sent to a sample of 2397 farmers. In Sweden, as much as $98 \%$ of the population has access to the Internet in the household (Internetstiftelsen, 2019), making the online survey mode an efficient way of collecting data without risk of biasing the sample due to poor Internet access. The sample was stratified according to the type of agricultural specialisation, size and geographical location. Smallholdings were not considered as this would bias our results towards farms that are often primarily used for other purposes (such as recreation) than for just business.

The addresses of farmers were obtained from Statistics Sweden. Farmers were invited to participate in the online survey by letter sent by regular mail. The letter contained general information about the larger project of which this study is a part, a link and a registration code to the online survey. After one reminder, a total of 432 responses were obtained. This represents a response rate of $18 \%$. Of these, 382 farmers agreed to participate in the study. The response rate is lower than that obtained in previous studies aimed at Swedish farmers (Hansson et al., 2013; Manevska-Tasevska et al., 2017) but comparable to the response rate of $19 \%$ obtained in a study aimed at dairy farmers in the Netherlands (Sok et al., 2018).

\subsection{Statistical methods}

Our interest was in assessing the empirical content and structure of Swedish farmers' POBD, and how differences in the latent variable perceived obstacles for business development $\eta$ can be explained by personal values and personality traits. The measured perceptions about obstacles (Section 2.2.1) were used as indicators for a latent variable that represents the above-mentioned construct. Personal values and personality traits (Section 2.2.2) were assumed to act as covariates, explaining individual differences and heterogeneity in goals.

Latent variables are mostly constructed by factor-analytical techniques that treat the observed variables, i.e. the set of perceived obstacles, as so-called reflective indicators (e.g. Coltman et al., 2008). The set of perceived obstacles is modelled as a function of the latent variable, and a good fit requires shared variance among the perceptions. Reflective indicators are assumed to have 'conceptual unity', they should all correspond to the same concept or dimension (Bollen and Bauldry, 2011). A change in the construct should be reflected in changes in all obstacles included in the model.

Bollen and Diamantopolous (2017) suggest using 'mental experiments' to decide whether an observed variable is reflective or formative in nature. "A researcher should imagine a change in the indicator and ask whether this change is likely to change the value of the latent variable. If so, this is theoretical evidence supporting causal or formative indicators. Alternatively, the researcher should imagine changing the latent variable and ask whether this is likely to change the value of the indicator(s). If so, this favours reflective (effect) indicators." (Bollen and Diamantopoulos, 2017).

Given the above, assuming reflective indicators for the statements that measure farmers' perceived current and prospective profitability is reasonable; scores on indicators capturing POBD are most likely 
reflected in how farmers perceive current and future profitability. For all other obstacles that relate to aspects such as financial resources, business partners, or institutional or geographical settings, we presumed formative indicators are theoretically more appropriate to represent them in the modelling (see e.g. Bollen and Lennox, 1991). With the latter type of indicator, potential obstacles, such as lack of financial resources, poor advisory services, legislation issues or the farm layout, are conceptualised as causes of the latent variable. The direction of causality is modelled from the observed variable to its construct. A change in one formative indicator can independently from other indicators result in a change in the construct.

A multiple indicators and multiple causes (MIMIC) model, introduced by Jöreskog and Goldberger (1975) and popularised by Diamantopoulos and colleagues (2008; 2001), estimates a latent variable using both reflective and formative indicators. MIMIC models are used by a wide range of social scientists: economists, psychologists and sociologists. Schematically, our modelling approach is represented in Fig. 1.

The reflective indicators are modelled as:

$y=\lambda \eta+\varepsilon$

where $y$ is a vector that contains the two profitability perception scores considered as reflective in nature, $\eta$ the latent variable, which is the construct $\mathrm{POBD}$, and $\varepsilon$ is a random vector that contains measurement errors. Equation (1) can be seen as a confirmatory factor analysis model with one common factor. $\lambda$, the so-called factor loadings, will give the effect of the latent variable on $\gamma$. It is further assumed that $\varepsilon$ is normally distributed with zero means and diagonal covariance matrices.

The formative indicators and covariates are modelled as:

$\eta=\gamma^{\prime} x+\delta^{\prime} z+\zeta$

where $x$ is a vector that contains all obstacle perception scores other than the two profitability perceptions, $z$ is a vector that contains the personal values and personality traits scores, and $\zeta$ is a random vector that captures the impact of factors not modelled. $\gamma$ indicates the contribution of each perception on $\eta$, while the significant $\delta$ indicates which values or traits explain individual differences at construct level. It is further assumed that $\zeta$ is normally distributed with zero means and diagonal covariance matrices.

The MIMIC model is estimated by the reduced form equation in which Eq. (2) is substituted into Eq. (1). For details on identification and estimation of MIMIC models, we refer to the seminal article of Jöreskog and Goldberger (1975), and more recent articles of Bollen and various co-authors (2011; 2009; 2017).

\section{Results}

\subsection{Characterising the sample}

Among the returned set of 382 surveys obtained from the farmers who agreed to participate in the study, some sections of individual surveys were not completed. The highest numbers of missing values were found in statements measuring personality traits and personal values. We report descriptive statistics of respondents who completed their survey, to have the number of respondents equal across analyses. Table 1 reports on characteristics of both the respondents and their farm. The majority of the respondents were male. Education levels among the respondents vary fairly equally from primary school only to university. There were very few young and early career farmers in the sample, as only $7.1 \%$ were 45 years old or less. About one third of the farmers were over 65 years old while only $15.8 \%$ of the respondents indicated that they were certain of a successor at their farm. These observations reflect the ageing farmer population in Sweden and point to farm succession as a potential obstacle for business development.

Half of the respondents ran farms with mainly animal production, followed by farms with mainly crop production (38\%) and mixed farms $(12 \%)$. Furthermore, differences in hectares of owned land - both arable and pasture - show that farm size and type was heterogeneous in the sample. A total of $10.6 \%$ of farmers had more than 180 ha of arable land, while $39 \%$ of farmers had less than 20 ha of arable land. Slightly over half of the farms had diversified farm activities or planned starting such activities. The specific diversifying activities ticked most often were contract work, renting out apartments or houses, and on-farm shops.

Based on official statistics of the Swedish agricultural sector (Statistics Sweden and Swedish Board of Agriculture, 2017), it is possible to compare our sample to the whole population based on the type of farm operation and the gender of the farm operator. Based on this, it can be concluded that our sample has a significantly larger proportion of farms in animal production (p-value 0.022 ) and a smaller proportion of farms in crop production (p-value 0.005 ), while the proportion of farms in mixed production that are run by female farmers well resembles the population characteristics.

\subsection{Descriptive statistics of indicators}

In Table 2, we first distinguish reflective indicators (y-variables)

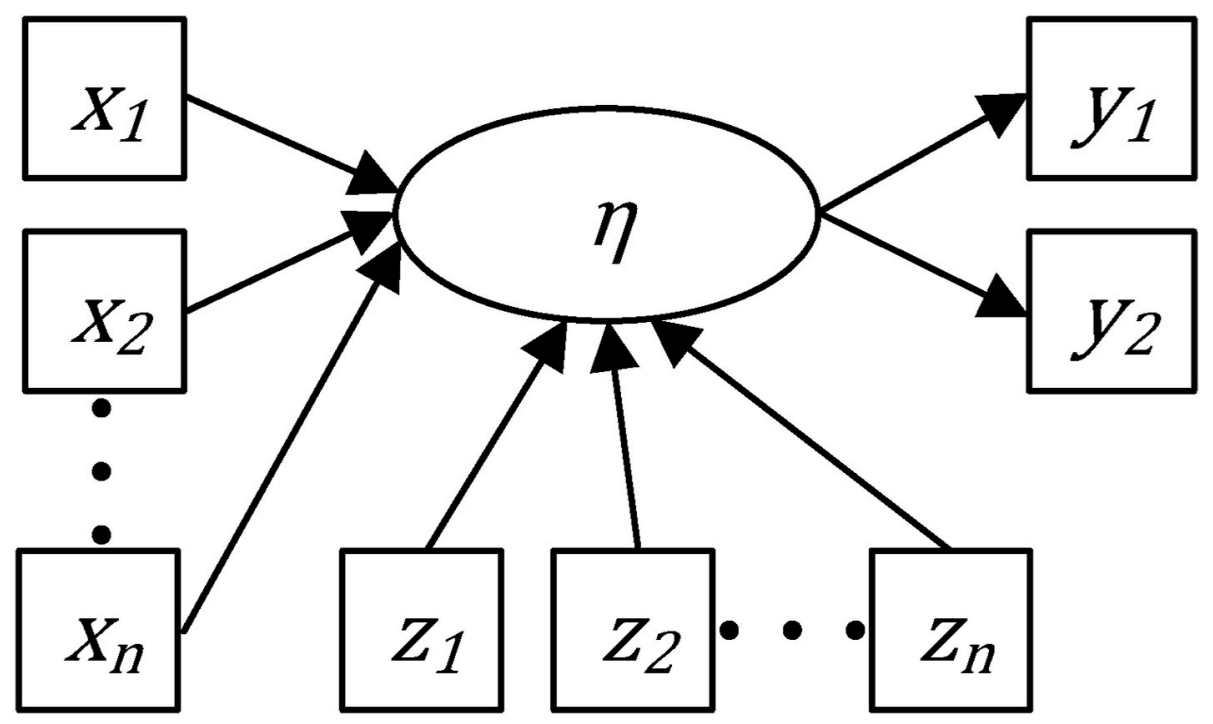

Fig. 1. Modelling approach. 
Table 1

Farmer and farm characteristics of survey respondents $(\mathrm{N}=254)$.

\begin{tabular}{|c|c|c|c|}
\hline Question/Answer & Percentage & Question/Answer & Percentage \\
\hline \multicolumn{2}{|l|}{ Gender of the respondent } & \multicolumn{2}{|l|}{ Successor } \\
\hline Male & 85.8 & No & 25.2 \\
\hline \multirow[t]{2}{*}{ Female } & 14.2 & Yes & 15.8 \\
\hline & & $\begin{array}{l}\text { Too early to say/ } \\
\text { don't know }\end{array}$ & 59.1 \\
\hline \multicolumn{2}{|c|}{ Highest level of education of respondent } & \multicolumn{2}{|c|}{$\begin{array}{l}\text { Number of hectares of owned } \\
\text { land (arable, pasture) }\end{array}$} \\
\hline Primary school & 16.5 & $\leq 20$ & $39.0,64.2$ \\
\hline $\begin{array}{l}\text { Gymnasium (upper secondary } \\
\text { school) }\end{array}$ & 20.1 & $>20$ and $\leq 60$ & $27.5,9.0$ \\
\hline $\begin{array}{l}\text { Agricultural gymnasium } \\
\text { (upper secondary school) }\end{array}$ & 20.9 & $>60$ and $\leq 180$ & $17.4,1.2$ \\
\hline $\begin{array}{l}\text { Lantmästare (agricultural } \\
\text { college) }\end{array}$ & 14.2 & $>180$ & $10.6,1.2$ \\
\hline $\begin{array}{l}\text { Agronomist/other university } \\
\text { training }\end{array}$ & 26.8 & None & $5.5,24.4$ \\
\hline $\begin{array}{l}\text { Other education (only or in } \\
\text { addition) }\end{array}$ & 23.6 & & \\
\hline \multicolumn{2}{|l|}{ Current age of respondent } & \multicolumn{2}{|l|}{$\begin{array}{l}\text { Diversified farm } \\
\text { activities }\end{array}$} \\
\hline$\leq 45$ & 7.1 & Yes & 48.4 \\
\hline$>45$ and $\leq 65$ & 58.3 & No & 48.4 \\
\hline$>65$ & 34.6 & Planning to start & 3.2 \\
\hline \multicolumn{2}{|c|}{ Starting year of operating the farm } & \multicolumn{2}{|c|}{$\begin{array}{l}\text { Distance }(\mathrm{km}) \text { to closest village } \\
\text { with } \geq 3000 \text { inhabitants, town } \\
\text { with } \geq 30,000 \text { inhabitants }\end{array}$} \\
\hline$\leq 1980$ & 15.8 & $\leq 10$ & $50.0,16.5$ \\
\hline$>1980$ and $\leq 2000$ & 48.4 & $>10$ and $\leq 25$ & $33.9,31.9$ \\
\hline \multirow{2}{*}{$>2000$} & 35.8 & $>25$ and $\leq 75$ & $15.0,39.8$ \\
\hline & & $>75$ & $1.1,11.8$ \\
\hline Type of farm operation & 38.0 & & \\
\hline Mainly crop production & 50.0 & & \\
\hline Mainly animal production & 12.0 & & \\
\hline
\end{tabular}

Note: Number of observations (N) is lower than the actual responses to the survey. This is due to missing values in responses to individual questions.

from formative indicators ( $x$-variables). We further report the mean and standard deviation value for each perceived obstacle indicator, and, for each formative indicator, its correlation with the average of both $y$-variables. Sorting is done based on perceived obstacle indicator, not on the mean.

Farmers, on average, perceive certain obstacles for business development being more constraining than others. Mean values range from 5.67 (rules and regulation) to 3.78 (lack of support from business partners). At the same time, there is also a variation within each perceived obstacle. SD values are always larger than 2 , with the most variation found in the perceived obstacle liquidity problems [ ...].

The highest mean values are found in the business management aspects of finance, law and regulation, marketing, and resource acquisition. Within the finance class, the obstacle not enough own financial resources is considered the most constraining obstacle. Furthermore, within the law and regulation class, the obstacle rules and regulation is perceived as influential for business development. The other indicators measuring for specific legislation around land use were scored lower. The rules and regulation obstacle, however, measures farmers' perceptions very generally and can encompass many considerations; its correlation with the average of the profitability indicators is only moderate.

Respondents seem to perceive the marketing of their products as an obstacle for business development. The policy agenda for Swedish agriculture and food production prioritises more organic production, better animal welfare and rural development (Swedish Government, 2017). Consumer demand for my products has a high correlation with the average of the profitability indicators.

The respondents further indicated that they perceive problems with available resources. The acquisition of land, either by owning or leasing, was measured specifically, and mean values indicate having insufficient land is an obstacle for business development. Correlation values suggest,
Table 2

Description and some descriptive statistics of the perceived obstacle indicators measured in the survey.

\begin{tabular}{|c|c|c|c|}
\hline Var. & Perceived obstacle indicators & $\begin{array}{l}\text { Mean } \\
(\mathrm{SD})\end{array}$ & $\begin{array}{l}\text { Corr. } \\
\text { with } \bar{y}\end{array}$ \\
\hline$y_{1}$ & Poor profitability & $\begin{array}{l}5.37 \\
(2.43)\end{array}$ & - \\
\hline \multirow[t]{2}{*}{$y_{2}$} & Poor forecasted profitability in future investments & $\begin{array}{l}5.31 \\
(2.22)\end{array}$ & - \\
\hline & Finance & & \\
\hline$x_{11}$ & Not enough own financial resources & $\begin{array}{l}5.48 \\
(2.43)\end{array}$ & 0.49 \\
\hline$x_{12}$ & Liquidity problems, cannot pay bills on time & $\begin{array}{l}4.88 \\
(2.91)\end{array}$ & 0.51 \\
\hline$x_{13}$ & Getting bank loans approved & $\begin{array}{l}4.54 \\
(2.73)\end{array}$ & 0.52 \\
\hline$x_{14}$ & $\begin{array}{l}\text { Not enough external financial resources (e.g. from } \\
\text { business partners) } \\
\text { Geography and planning }\end{array}$ & $\begin{array}{l}4.26 \\
(2.55)\end{array}$ & 0.20 \\
\hline$x_{21}$ & Poor infrastructure & $\begin{array}{l}4.41 \\
(2.44)\end{array}$ & 0.32 \\
\hline$x_{22}$ & Poor farm layout & $\begin{array}{l}4.23 \\
(2.25)\end{array}$ & 0.25 \\
\hline \multirow[t]{2}{*}{$x_{23}$} & Farm geographic location & $\begin{array}{l}3.94 \\
(2.30)\end{array}$ & 0.20 \\
\hline & Knowledge and innovation & & \\
\hline$x_{31}$ & Poor knowledge and competences within the farm & $\begin{array}{l}4.69 \\
(2.46)\end{array}$ & 0.44 \\
\hline$x_{32}$ & Poor competences in farm network & $\begin{array}{l}4.34 \\
(2.21)\end{array}$ & 0.45 \\
\hline \multirow[t]{2}{*}{$x_{33}$} & Poor advisory services & $\begin{array}{l}4.13 \\
(2.26)\end{array}$ & 0.36 \\
\hline & Law and regulation & & \\
\hline$x_{41}$ & Rules and regulation & $\begin{array}{l}5.67 \\
(2.18)\end{array}$ & 0.30 \\
\hline$x_{42}$ & Legislation around farm lease & $\begin{array}{l}4.15 \\
(2.24)\end{array}$ & 0.27 \\
\hline \multirow[t]{2}{*}{$x_{43}$} & Land acquisition act & $\begin{array}{l}3.89 \\
(2.20)\end{array}$ & 0.23 \\
\hline & Marketing & & \\
\hline$x_{51}$ & Consumer demand for my products & $\begin{array}{l}5.32 \\
(2.49)\end{array}$ & 0.57 \\
\hline \multirow[t]{2}{*}{$x_{52}$} & Foreign competition & $\begin{array}{l}4.99 \\
(2.36)\end{array}$ & 0.36 \\
\hline & Resource acquisition & & \\
\hline$x_{61}$ & $\begin{array}{l}\text { Problems with available resources (equipment, } \\
\text { buildings, labour, etc.) }\end{array}$ & $\begin{array}{l}5.46 \\
(2.10)\end{array}$ & 0.60 \\
\hline$x_{62}$ & Poor possibilities to buy new farmland & $\begin{array}{l}5.22 \\
(2.27)\end{array}$ & 0.10 \\
\hline$x_{63}$ & Poor possibilities to lease land & $\begin{array}{l}4.91 \\
(2.38)\end{array}$ & 0.15 \\
\hline$x_{71}$ & $\begin{array}{l}\text { Social capital } \\
\text { Lack of support from family }\end{array}$ & $\begin{array}{l}4.82 \\
(2.68)\end{array}$ & 0.42 \\
\hline$x_{72}$ & Options for farm succession & $\begin{array}{l}4.70 \\
(2.54)\end{array}$ & 0.33 \\
\hline$x_{73}$ & Maintaining business relationships & $\begin{array}{l}4.43 \\
(2.12)\end{array}$ & 0.46 \\
\hline$x_{74}$ & Lack of support from business partners & $\begin{array}{l}3.78 \\
(2.44)\end{array}$ & 0.24 \\
\hline
\end{tabular}

however, that the availability of other resources (equipment, buildings, labour) is more urgent for profitability.

\subsection{Personality traits and personal values as covariates}

Before we test the POBD construct, we will report on the measurement and construction of two sets of covariates that we proposed to include in the models. These covariates are supposed to capture individual differences in farmers' perceptions of obstacles: personality traits and personal values.

Table 3 gives the correlations between each personality trait or value dimension (columns), and perceived obstacles for business development (rows). Univariate patterns observed are now discussed. First, we found 
Table 3

Correlations between perceived obstacle indicators (rows) and personality traits and value dimensions (columns).

\begin{tabular}{|c|c|c|c|c|c|c|c|c|}
\hline & \multirow{2}{*}{-} & \multicolumn{3}{|c|}{ Personality traits } & \multicolumn{4}{|c|}{ Value dimensions } \\
\hline & & $\mathrm{E}$ & A & Cs & $\mathrm{N}$ & $\mathrm{O}$ & S-T & $\mathrm{Cn}$ \\
\hline & & $z_{11}$ & $z_{12}$ & $z_{13}$ & $z_{14}$ & $z_{15}$ & $z_{21}$ & $z_{22}$ \\
\hline \multicolumn{9}{|l|}{ Perceived obstacle aspect } \\
\hline \multirow[t]{2}{*}{ Profitability } & $y_{1}$ & -0.14 & -0.04 & -0.02 & 0.16 & -0.03 & 0.01 & 0.09 \\
\hline & $y_{2}$ & -0.18 & -0.10 & -0.04 & 0.15 & 0.01 & 0.06 & 0.10 \\
\hline \multirow[t]{4}{*}{ Finance } & $x_{11}$ & 0.04 & 0.01 & 0.03 & 0.03 & -0.08 & 0.00 & 0.02 \\
\hline & $x_{12}$ & -0.03 & -0.11 & 0.00 & 0.08 & -0.07 & 0.05 & 0.05 \\
\hline & $x_{13}$ & -0.05 & -0.09 & -0.01 & 0.11 & -0.13 & 0.04 & 0.04 \\
\hline & $x_{14}$ & 0.01 & 0.01 & 0.03 & -0.04 & -0.05 & 0.06 & -0.03 \\
\hline \multirow[t]{3}{*}{ Geography and planning } & $x_{21}$ & -0.09 & 0.00 & -0.05 & 0.03 & -0.02 & 0.08 & 0.11 \\
\hline & $x_{22}$ & -0.04 & 0.00 & 0.04 & -0.02 & -0.05 & -0.06 & 0.10 \\
\hline & $x_{23}$ & -0.17 & -0.02 & -0.02 & 0.02 & -0.07 & -0.07 & 0.05 \\
\hline \multirow[t]{3}{*}{ Knowledge and innovation } & $x_{31}$ & -0.15 & -0.15 & -0.08 & 0.14 & -0.13 & 0.06 & 0.07 \\
\hline & $x_{32}$ & -0.16 & -0.17 & -0.01 & 0.07 & -0.06 & 0.01 & 0.08 \\
\hline & $x_{33}$ & -0.15 & -0.22 & 0.00 & 0.03 & -0.01 & 0.00 & 0.10 \\
\hline \multirow[t]{3}{*}{ Law and regulation } & $x_{41}$ & -0.04 & -0.10 & -0.04 & 0.11 & -0.04 & -0.03 & 0.11 \\
\hline & $x_{42}$ & -0.16 & -0.14 & 0.00 & 0.01 & -0.06 & 0.00 & 0.11 \\
\hline & $x_{43}$ & -0.10 & -0.13 & -0.01 & 0.01 & -0.04 & 0.00 & 0.06 \\
\hline \multirow[t]{2}{*}{ Marketing } & $x_{51}$ & -0.09 & -0.12 & 0.01 & 0.09 & -0.04 & -0.10 & 0.08 \\
\hline & $x_{52}$ & -0.11 & -0.05 & -0.03 & 0.02 & -0.06 & -0.03 & 0.08 \\
\hline \multirow[t]{3}{*}{ Resource acquisition } & $x_{61}$ & -0.13 & -0.07 & 0.03 & 0.14 & -0.13 & 0.03 & 0.02 \\
\hline & $x_{62}$ & -0.15 & 0.07 & 0.07 & 0.02 & -0.05 & -0.03 & 0.15 \\
\hline & $x_{63}$ & -0.12 & -0.01 & 0.06 & -0.02 & -0.05 & -0.05 & 0.17 \\
\hline \multirow[t]{4}{*}{ Social capital } & $x_{71}$ & -0.04 & -0.10 & -0.04 & 0.16 & -0.08 & 0.20 & 0.11 \\
\hline & $x_{72}$ & -0.01 & 0.00 & 0.02 & 0.13 & -0.08 & 0.07 & 0.10 \\
\hline & $x_{73}$ & -0.15 & -0.14 & 0.01 & 0.11 & -0.10 & 0.05 & 0.09 \\
\hline & $x_{74}$ & -0.10 & -0.18 & 0.01 & 0.09 & -0.03 & 0.05 & 0.05 \\
\hline
\end{tabular}

Note: Correlations that were not significant at the 0.05 level were made grey (more transparent).

only weak correlations; The highest association is between $x_{71}$ and S-T, and has a value of only 0.2 . Personality traits correlate more often with perceived obstacles than the value dimensions. The small size of the correlations indicates that personality traits and personal values are the more distal variables in the MIMIC models, they act as covariates 'to control and avoid bias in estimating the relations between measures and latent variable' (Bollen and Bauldry, 2011).

Extraversion has the most correlations of all personality traits with both reflective and formative indicators for perceived obstacles. Extraverted people are often social, active, energetic and optimistic (Antoncic et al., 2015; Zhao and Seibert, 2006). Correlatons indicate that the more extravert farmers expect fewer problems with profitability, access to the knowledge and innovation infrastructure, and with resource acquisition.

Farmers scoring higher on agreeableness can be characterised as trusting, forgiving, caring, altruistic, and having a preference for positive interpersonal relationships (Nuthall, 2018; Zhao and Seibert, 2006). We found many negative, moderating associations between higher scores on agreeableness and higher scores on obstacles that relate to the involvement of other actors: partners at own farm $\left(x_{31}\right)$, farm network $\left(x_{32}\right)$, advisory services $\left(x_{33}\right)$, government $\left(x_{42}\right.$ and $\left.x_{43}\right)$, consumers $\left(x_{51}\right)$, business partners $\left(x_{73}\right.$ and $\left.x_{74}\right)$.

Conscientiousness is not correlated with any of the perceived obstacles.

People that have a more entrepreneurial focus often score lower on neuroticism and higher on openness (Zhao and Seibert, 2006). We found that the more entrepreneurial-focused farmers scored lower on perceived obstacles getting bank loans approved, poor knowledge and competence [ ...], and problems with available resources [ ...]. (See Table 2 for explanation of the obstacles). Less neurotic farmers further scored lower on perceived poor profitability $\left(y_{1}\right.$ and $\left.y_{2}\right)$ and on obstacles lack of support from family and options for farm succession.

Farmers scoring high on the self-transcendence dimension tend to have 'concern for the welfare of other people', whereas farmers scoring low tend to have 'concern for individual outcomes and personal interests' (Lindeman and Verkasalo, 2005b). Self-transcendence only significantly correlated with lack of support from family, where a positive association was found. Farmers scoring high on the conservation dimension tend to 'preserve the status quo and the certainty that conformity to norms provides', whereas farmers scoring low tend to 'follow one's own intellectual and emotional interests'. Conservation is correlated with two perceived obstacles relating to the acquisition of land.

\subsection{MIMIC model fit and results}

In Table 4, we report the results of three MIMIC models. Model fit is assessed in various ways. The reflective indicators' fit is assessed using the size of the factor loading (which should ideally be 0.7 or higher). For the formative indicators, we follow an approach suggested by Franke et al. (2008) to check proportionality constraints by inspecting modification indices (Sörbom, 1989). The latter estimates the change in model fit from freeing a constrained parameter. If direct relationships between formative and reflective indicators are suggested to improve model fit, this is an indication that the formative conceptualisation of the construct is not fully appropriate. Overall, model fit is assessed using several statistics that are commonly used in the SEM literature (see e.g. Kline, 2011).

Model 1 has only reflective indicators for the POBD construct, and, as such, only takes profitability aspects into account. Model fit is appropriate: factor loadings are above 0.7 and the overall model fit criteria meet the cut-off values. The covariates personality traits and personal values only explain $7 \%$ of the variance in the constructs, which is based on reflective indicators of perceived profitability only.

Model 2 adds the main effects of selected formative indicators to the MIMIC model after removing, in steps, the non-significant indicators 
Table 4

MIMIC model for latent variable perceived obstacles for business development.

\begin{tabular}{|c|c|c|c|c|c|c|c|}
\hline & & \multicolumn{2}{|c|}{$\begin{array}{l}1 \\
\text { Covariates and reflective indicators only }\end{array}$} & \multicolumn{2}{|c|}{$\begin{array}{l}2 \\
+ \text { main effects formative indicators }\end{array}$} & \multicolumn{2}{|c|}{$\begin{array}{l}3 \\
+ \text { interaction effects formative indicators }\end{array}$} \\
\hline & & Coef. & P-value & Coef. & $\mathrm{P}$-value & Coef. & $\mathrm{P}$-value \\
\hline \multicolumn{8}{|l|}{ Covariates } \\
\hline Extraversion & $z_{11}$ & -0.14 & 0.043 & -0.12 & 0.008 & -0.15 & 0.001 \\
\hline Agreeableness & $z_{12}$ & -0.05 & 0.478 & 0.02 & 0.662 & 0.00 & 0.973 \\
\hline Conscientiousness & $z_{13}$ & 0.01 & 0.905 & -0.03 & 0.464 & -0.04 & 0.377 \\
\hline Neuroticism & $z_{14}$ & 0.15 & 0.042 & 0.04 & 0.353 & 0.05 & 0.224 \\
\hline Openness & $z_{15}$ & 0.05 & 0.470 & 0.12 & 0.008 & 0.12 & 0.006 \\
\hline Self-transcendence & $z_{21}$ & 0.06 & 0.347 & 0.04 & 0.423 & 0.04 & 0.385 \\
\hline Conservation & $z_{22}$ & 0.09 & 0.187 & 0.06 & 0.200 & 0.02 & 0.587 \\
\hline \multicolumn{8}{|l|}{ Formative indicators } \\
\hline Not enough own financial resources & $x_{11}$ & & & 0.16 & 0.008 & 0.18 & 0.002 \\
\hline Getting bank loans approved & $x_{13}$ & & & 0.22 & 0.000 & 0.18 & 0.237 \\
\hline Poor farm layout & $x_{22}$ & & & 0.15 & 0.000 & 0.45 & 0.000 \\
\hline Farm geographic location & $x_{23}$ & & & -0.20 & 0.000 & -0.54 & 0.000 \\
\hline Consumer demand for my products & $x_{51}$ & & & 0.27 & 0.000 & 0.39 & 0.000 \\
\hline Problems with available resources & $x_{61}$ & & & 0.41 & 0.001 & 0.25 & 0.004 \\
\hline \multirow[t]{6}{*}{ Options for farm succession } & $x_{72}$ & & & 0.17 & 0.008 & 0.19 & 0.065 \\
\hline & $x_{13} x_{61}$ & & & & & 0.32 & 0.051 \\
\hline & $x_{13} x_{72}$ & & & & & -0.29 & 0.023 \\
\hline & $x_{22} x_{72}$ & & & & & -0.28 & 0.096 \\
\hline & $x_{23} x_{51}$ & & & & & -0.24 & 0.079 \\
\hline & $x_{23} x_{72}$ & & & & & 0.57 & 0.000 \\
\hline Variance explained & & & 0.07 & & 0.74 & & 0.78 \\
\hline \multicolumn{8}{|l|}{ Reflective indicators } \\
\hline Poor profitability & $y_{1}$ & 0.74 & 0.00 & 0.84 & 0.000 & 0.84 & 0.000 \\
\hline$[\ldots]$ profitability in future investments & $y_{2}$ & 0.94 & 0.00 & 0.82 & 0.000 & 0.83 & 0.000 \\
\hline \multicolumn{8}{|l|}{ Diagnostic statistics of the model } \\
\hline$\chi^{2}$ & & \multicolumn{2}{|l|}{3.31} & \multicolumn{2}{|l|}{17.05} & \multicolumn{2}{|l|}{26.65} \\
\hline $\mathrm{df}$ & & \multicolumn{2}{|l|}{6} & \multicolumn{2}{|l|}{13} & \multicolumn{2}{|l|}{18} \\
\hline$p$ & & \multicolumn{2}{|l|}{0.769} & \multicolumn{2}{|l|}{0.197} & \multicolumn{2}{|l|}{0.086} \\
\hline RMSEA (90\% CI) & & \multicolumn{2}{|c|}{$0.000(0-0.056)$} & \multicolumn{2}{|c|}{$0.035(0-0.076)$} & \multicolumn{2}{|c|}{$0.043(0-0.076)$} \\
\hline$p_{\text {closefit } H_{0}}$ & & \multicolumn{2}{|c|}{0.932} & \multicolumn{2}{|l|}{0.680} & \multicolumn{2}{|l|}{0.587} \\
\hline CFI & & \multicolumn{2}{|l|}{1.000} & \multicolumn{2}{|l|}{0.990} & \multicolumn{2}{|l|}{0.979} \\
\hline SRMR & & \multicolumn{2}{|l|}{0.010} & 0.011 & & 0.009 & \\
\hline
\end{tabular}

that exceed a significance level of $5 \%$ (Diamantopoulos and Winklhofer, 2001). Model fit is satisfactory, and compared to Model 1 , the formative indicators explain an additional $67 \%$ of the variance in the latent variable. Modification indices suggest four omitted relationships that could marginally improve model fit: between $x_{11}, x_{51}$ and both reflective indicators. We decided not to free these relationships based on arguments Bollen and Diamantopolous (2017) put forward.

Following Winklhofer and Diamantopolous (2002), in Model 3, we added interaction effects after a similar selection procedure used to select the main effects. The cut-off value used here was a significance level of $10 \%$. Modification indices now only suggest omitted relationships between $x_{11}$ and $y_{1}$ and $y_{2}$. An additional $4 \%$ of the variance is explained.

The effect of extraversion on the construct POBD remains stable over all models. Openness substitutes neuroticism as a personality trait that can explain individual differences when formative indicators enter the model. Both traits link to entrepreneurial behaviour (Leutner et al., 2014; Zhao and Seibert, 2006; Zhao et al., 2010).

Seven of the 24 formative indicators remained in the MIMIC model. Indicators of the business management aspects 'Knowledge and innovation' and 'Law and regulation' all disappeared from the final models. Resource acquisition and financing issues are clearly part of the

\footnotetext{
1 They argue that this situation is equal e.g. imposing a correlation between the measurement errors of two reflective indicators, which is something commonly practiced in SEM.
}

construct. Model 3 suggests that getting bank loans approved is conditional on problems with available resources and on options for farm succession. The latter variables also have a significant positive main effect on the construct.

Next to resource acquisition and financing issues, the marketing of agricultural products is part of the construct. Consumer demand for my products, in Model 3, is conditional on how farmers perceive their geographical location as an obstacle for business development. Geographical and planning issues are also part of the construct. The obstacle farm geographic location has a negative coefficient, while the correlation with the reflective indicators was positive (Table 2). The obstacle poor farm layout is only significant when farm geographic location is retained; we conclude the latter indicator is a negative suppressor (Maassen and Bakker, 2001). ${ }^{2}$ Both these variables interact with options for farm succession.

As a robustness check, we finally re-ran the three models by excluding 12 respondents ( $4.7 \%$ of the sample) who displayed a nondifferentiation or 'straightlining' response strategy to the perceived obstacle indicators (Krosnick, 1991). The selection of formative indicators and associations between indicators and personality traits found did not change.

\footnotetext{
2 'Although the suppressor has relevant information in common with $\mathrm{Y}$, it share fewer common elements than the common elements of irrelevant information shared by the suppressor and the other predictor' (Maassen and Bakker, 2001).
} 


\section{Discussion and conclusions}

We had two objectives in this study; first, to assess the empirical content and structure of farmers' POBD that prevents them from developing their businesses in their preferred way; second, to explore how individual differences (in terms of personality and personal values) between farmers are related to these perceptions. Looking at the first objective, the findings suggest that the surveyed farmers' POBD consists of seven items, which can be grouped into the following areas: access to financial resources; farm characteristics in terms of layout and geographical location; consumer demand; available resources and options for farm succession. Thus, these are the main barriers the surveyed farmers perceive in developing their businesses in their preferred way and towards which policy could focus in order to contribute to more viable agricultural sectors. The sizes of the coefficients suggest the relative importance of the individual items. According to model specification 2, containing only main effects, problems with available resources seem to be the most important item of the latent variable, followed by consumer demand. The least important item appears to be poor farm layout, which has the smallest coefficient. Note, however, that this perception was only retained in the model if the farm geographic location perception was retained as well. The significant interaction effects in model specification 3 made it clear that most of the perceptions that were retained after the model selection procedure are closely connected to each other. Thus, really providing a firm ranking of the most important items is difficult to establish; the items retained can best be evaluated in coherence.

It is also interesting to note which items did not become part of the latent variable POBD. These are related to the financial situation of the farm; poor infrastructure; knowledge and innovation; laws and regulations; foreign competition; possibilities to buy or lease land; and support from family and business partners and relationships. Items related to these are not significant parts of the latent variable, signalling that business development is not perceived as being constrained by those aspects among the surveyed farmers. From a policy perspective, the findings indicate that initiatives focusing on these areas may be better used if they are shifted more towards the areas represented by the items that appear as significant parts of the construct, at least for policy aimed at farmers similar to the surveyed ones.

As a second objective, we explored how farmers' $\mathrm{POBD}$ are related to their individual differences, focusing on personal values (Schwartz, 1992, 2012) and on personality in terms of the Big Five model (John et al., 1991, 2008). The findings suggest that the construct is not so much related to personal values, but to personality traits in terms of extraversion and openness. This is interesting from the perspective that personal values have been described as being adjustable to environmental factors, whereas personality traits are more stable over time (Parks and Guay, 2009). This observation indicates that the surveyed farmers' POBD are more related to individual differences of the type that are relatively stable over time; thus, there seems to be a correlation with innate characteristics rather than with characteristics that are adjustable according to environmental factors. It is also interesting to note that the personality traits of extraversion and openness that are statistically significantly related to the latent variable have also been associated with entrepreneurial behaviour (Leutner et al., 2014; Zhao and Seibert, 2006; Zhao et al., 2010). In this respect, extraversion was here found positively related to the latent variable, suggesting that a personality type which is more outgoing and social also tends to perceive obstacles with less intensity. One reason for this can be that individuals with such a personality trait are more likely to discuss obstacles with others and through this process obtain inspiration about how to overcome them. On the other hand, a personality type more related to active imagination and artistic interests tends to perceive obstacles with higher intensity. A possible reason is that individuals with high levels on the openness personality trait may come up with more unconventional ways of developing their businesses, and therefore perceive obstacles more intensly. When researchers consider measuring individual differences among farmers, we recommend carefully assessing the role of personality traits and personal values before more certain conclusions can be drawn about their impact on the construct. We suggest using more narrow measurements of values and personality traits. For values, alternatives exist which are more specifically targeted towards agriculture, such as those described by Gasson (1973) and by Ferguson and Hansson (2013). The personal value scale by Schwartz (1992), and Schwartz (2012), although validated through cross-cultural datasets (Schwartz and Boehnke, 2004) may be too general to be able to capture the effects of individual differences in a specific domain like the one of interest here. For personality traits, instead of measuring broad traits such as extraversion and openness, one could consider a narrow trait such as innovativeness (Leutner et al., 2014).

Findings thus give insight into which obstacles the surveyed farmers feel prevent them from developing their business in their preferred way and how such perceptions are related to personal values and personality. As such, conclusions based on particular obstacles and impact of personal values and personality are mostly relevant for Swedish stakeholders and for stakeholders in countries with similar preconditions. Farmers in other countries and regions that are fundamentally different from Sweden may perceive other obstacles as more pressing. The research approach developed here could be useful for analysing their POBD, which would be informative for policy-making and advisory services aimed at promoting more vital agricultural sectors and would provide further background for more regionally differentiated policymaking and advisory services. Thus, future research could focus on testing the construct among farmers in different countries and regions. Furthermore, farmers with different types of specialisation may differ in their POBD and future research could also focus on investigating how differences in specialisation affect the POBD. This would also provide further evidence for better targeted policy formulation and advisory services.

Having said that, policy recommendations applicable to Swedish agriculture and to agriculture in similar countries and regions can be made from the findings regarding perceptions of obstacles. Obstacles such as access to financial resources and the type of resources available are likely possible to handle via existing programmes promoting investments aimed at promoting restructuring and innovations. The investment support in the Rural Development Programme is an example of such a policy measure. However, other significant parts of the latent variable likely require other types of effort, done jointly between policy makers, farmers and other actors in the agricultural sectors. Examples include improved skills and competences to adjust to current consumer demands, the undertaking of activities to affect demand and improved concepts for how farm succession can take place within and outside family. The findings indicate that the construct is also built around items related to farm layout and geographical location. From a policy perspective, this points to the need for regionally adjusting policy, which can facilitate the possibilities of making better use of agricultural resources in areas that are geographically disadvantageous and/or that are associated with poor farm layout. Findings also point to the fact that individual differences between farmers play a role in explaining how they perceive obstacles for business development. Although more research is needed to more fully explain these relationships, results presented here highlight the need of advisors who work with individual farmers to adapt advice carefully depending on characteristics of the individual. Practically this could be done by segmenting farmers according to their individual characteristics and place specific emphasise on POBD which are associated with specific segments and in advisory sessions discuss how such obstacles can be handled.

Future research can also use the POBD construct developed here. A promising research avenue goes beyond testing the construct in different settings or improving measurements. We suggest combining the measurement of the latent variable of POBD with survey experiments, such as a vignette study or a discrete choice experiment. These integrations 
will not only allow for the identification of the main perceived obstacles, but also for them to be assessed in relation to farmers' preferences for policy attributes and how these can make compliance or participation with policy more likely. Such a framework is known as an integrated choice and latent variable model or hybrid choice model (Ben-Akiva et al., 2012; Walker and Ben-Akiva, 2002). An application in the context of livestock disease control has been published (Sok et al., 2018). Such models could also provide a comprehensive base for modelling the behaviour of farmers in agent-based models (Sok and Fischer, 2019), also of significant policy relevance.

\section{Author statement}

First authorship is shared. Term: H Hansson, J Sok. Conceptualisation: H Hansson, J Sok. Data curation: H Hansson. Formal analysis: J Sok. Funding acquisition: Not applicable. Investigation: H Hansson. Methodology: J Sok, H Hansson. Project administration: H Hansson. Resources: H Hansson. Software: J Sok. Supervision: Not applicable . Validation: Equal contribution. Visualization: Not applicable. Roles/ writing-original draft: Equal contribution. Writing - review and editing: Equal contribution.

\section{Acknowledgements}

Authors contributed equally to this paper; first authorship is shared.

\section{Appendix A. Supplementary data}

Supplementary data to this article can be found online at https://doi. org/10.1016/j.jrurstud.2020.12.004.

\section{References}

Adrian, A.M., Norwood, S.H., Mask, P.L., 2005. Producers' perceptions and attitudes toward precision agriculture technologies. Comput. Electron. Agric. 48, 256-271.

Antoncic, B., Bratkovic Kregar, T., Singh, G., DeNoble, A.F., 2015. The big five personality-entrepreneurship relationship: evidence from Slovenia. J. Small Bus. Manag. 53, 819-841.

Barbieri, C., Mahoney, E., 2009. Why is diversification an attractive farm adjustment strategy? Insights from Texas farmers and ranchers. J. Rural Stud. 25, 58-66.

Bardi, A., Schwartz, S.H., 2003. Values and behavior: strength and structure of relations. Pers. Soc. Psychol. Bull. 29, 1207-1220.

Barnes, A.P., Hansson, H., Manevska-Tasevska, G., Shrestha, S.S., Thomson, S.G., 2015. The influence of diversification on long-term viability of the agricultural sector. Land Use Pol. 49, 404-412.

Ben-Akiva, M., de Palma, A., McFadden, D., Abou-Zeid, M., Chiappori, P.-A., de Lapparent, M., Durlauf, S., Fosgerau, M., Fukuda, D., Hess, S., Manski, C., Pakes, A., Picard, N., Walker, J., 2012. Process and context in choice models. Market. Lett. 23, 439-456.

Bollen, K.A., Bauldry, S., 2011. Three Cs in measurement models: causal indicators, composite indicators, and covariates. Psychol. Methods 16, 265-284.

Bollen, K.A., Davis, W.R., 2009. Causal indicator models: identification, estimation, and testing. Struct. Equ. Model.: A Multidisciplinary Journal 16, 498-522.

Bollen, K.A., Diamantopoulos, A., 2017. In defense of causal-formative indicators: a minority report. Psychol. Methods 22, 581-596.

Bollen, K., Lennox, R., 1991. Conventional wisdom on measurement: a structural equation perspective. Psychol. Bull. 110, 305-314.

Brandstätter, H., 2011. Personality aspects of entrepreneurship: a look at five metaanalyses. Pers. Indiv. Differ. 51, 222-230.

Coltman, T., Devinney, T.M., Midgley, D.F., Venaik, S., 2008. Formative versus reflective measurement models: two applications of formative measurement. J. Bus. Res. 61, 1250-1262.

Dessart, F.J., Barreiro-Hurlé, J., van Bavel, R., 2019. Behavioural factors affecting the adoption of sustainable farming practices: a policy-oriented review. Eur. Rev. Agric. Econ. 46, 417-471.

Diamantopoulos, A., Winklhofer, H.M., 2001. Index construction with formative indicators: an alternative to scale development. J. Market. Res. 38, 269-277.

Diamantopoulos, A., Riefler, P., Roth, K.P., 2008. Advancing formative measurement models. J. Bus. Res. 61, 1203-1218.

European Commission, 2017. Communication from the Commission to the European Parliament, the Council, the European Economic and Social Committee and the Commitee of the Regions the Future of Food and Farming.

Fayolle, A., Liñán, F., Moriano, J.A., 2014. Beyond entrepreneurial intentions: values and motivations in entrepreneurship. Int. Enterpren. Manag. J. 10, 679-689.

Ferguson, R., Hansson, H., 2013. Expand or exit? Strategic decisions in milk production. Livest. Sci. 155, 415-423.
Franke, G.R., Preacher, K.J., Rigdon, E.E., 2008. Proportional structural effects of formative indicators. J. Bus. Res. 61, 1229-1237.

Gasson, R., 1973. Goals and values OF farmers. J. Agric. Econ. 24, 521-542.

Gutman, J., 1982. A means-end chain model based on consumer categorization processes. J. Market. 46, 60-72.

Hansson, H., Ferguson, R., Olofsson, C., Rantamäki-Lahtinen, L., 2013. Farmers' motives for diversifying their farm business - the influence of family. J. Rural Stud. 32, 240-250.

Hansson, H., Thompson, B., Manevska-Tasevska, G., Toma, L., Leduc, G., Vranken, L., 2019. Drivers of farmers' up-take of ecological approaches - a conceptual framework with a behavioural focus. LIFT Deliverable D2 1.

Howley, P., 2015. The happy farmer: the effect of nonpecuniary benefits on behavior. Am. J. Agric. Econ. 97, 1072-1086.

Huber, R., Bakker, M., Balmann, A., Berger, T., Bithell, M., Brown, C., Grêt-Regamey, A., Xiong, H., Le, Q.B., Mack, G., Meyfroidt, P., Millington, J., Müller, B., Polhill, J.G., Sun, Z., Seidl, R., Troost, C., Finger, R., 2018. Representation of decision-making in European agricultural agent-based models. Agric. Syst. 167, 143-160.

Internetstiftelsen, 2019. Svenskarna Och Internet 2019.

John, O.P., Donahue, E.M., Kentle, R.L., 1991. The "big five" inventory: versions 4a and 54. The Big Five Inventory 4a, 54.

John, O.P., Naumann, L.P., Soto, C.J., 2008. Paradigm shift to the integrative Big Five trait taxonomy: history, measurement, and conceptual issues. Handbook of Personality: Theory and Research 114-158.

Jöreskog, K.G., Goldberger, A.S., 1975. Estimation of a model with multiple indicators and multiple causes of a single latent variable. J. Am. Stat. Assoc. 70, 631-639.

Kline, R.B., 2011. Principles and Practice of Structural Equation Modeling, 3nd ed. The Guilford Press, New York.

Kollmann, T., Stöckmann, C., Kensbock, J.M., 2017. Fear of failure as a mediator of the relationship between obstacles and nascent entrepreneurial activity—an experimental approach. J. Bus. Ventur. 32, 280-301.

Kotey, B., Meredith, G.G., 1997. Relationships among owner/manager personal values, business strategies, and enterprise performance. J. Small Bus. Manag. 35, 37-64.

Krosnick, J.A., 1991. Response strategies for coping with the cognitive demands of attitude measures in surveys. Appl. Cognit. Psychol. 5, 213-236.

Leutner, F., Ahmetoglu, G., Akhtar, R., Chamorro-Premuzic, T., 2014. The relationship between the entrepreneurial personality and the Big Five personality traits. Pers. Indiv. Differ. 63, 58-63.

Lindeman, M., Verkasalo, M., 2005a. Measuring values with the short schwartz's value survey. J. Pers. Assess. 85, 170-178.

Lindeman, M., Verkasalo, M., 2005b. Measuring values with the short schwartz's value survey. J. Pers. Assess. 85, 170-178.

Long, T.B., Blok, V., Coninx, I., 2016. Barriers to the adoption and diffusion of technological innovations for climate-smart agriculture in Europe: evidence from The Netherlands, France, Switzerland and Italy. J. Clean. Prod. 112, 9-21.

Maassen, G.H., Bakker, A.B., 2001. Suppressor variables in path models: definitions and interpretations. Socio. Methods Res. 30, 241-270.

Manevska-Tasevska, G., Hansson, H., Labajova, K., 2017. Impact of management practices on persistent and residual technical efficiency - a study of Swedish pig farming. Manag. Decis. Econ. 38, 890-905.

May, D., Arancibia, S., Behrendt, K., Adams, J., 2019. Preventing young farmers from leaving the farm: investigating the effectiveness of the young farmer payment using a behavioural approach. Land Use Pol. 82, 317-327.

Nuthall, P.L., 2018. Farm Business Management : the Human Factor. CABI, Boston, MA.

Olson, J.C., 1989. Theoretical foundations of means-end chains. Werbeforschung \& Praxis 5, 174-178.

Olver, J.M., Mooradian, T.A., 2003. Personality traits and personal values: a conceptual and empirical integration. Pers. Indiv. Differ. 35, 109-125.

Parks, L., Guay, R.P., 2009. Personality, values, and motivation. Pers. Indiv. Differ. 47, 675-684.

Parks-Leduc, L., Feldman, G., Bardi, A., 2015. Personality traits and personal values: a meta-analysis. Pers. Soc. Psychol. Rev. 19, 3-29.

Phillipson, J., Tiwasing, P., Gorton, M., Maioli, S., Newbery, R., Turner, R., 2018. Shining a spotlight on small rural businesses: how does their performance compare with urban? J. Rural Stud. 68, 230-239.

Pietola, K., Lansink, A., 2001. Farmer response to policies promoting organic farming technologies in Finland. Eur. Rev. Agric. Econ. 28, 1-15.

Rammstedt, B., John, O.P., 2007. Measuring personality in one minute or less: a 10-item short version of the Big Five Inventory in English and German. J. Res. Pers. 41, 203-212.

Reichardt, M., Jürgens, C., Klöble, U., Hüter, J., Moser, K., 2009. Dissemination of precision farming in Germany: acceptance, adoption, obstacles, knowledge transfer and training activities. Precis. Agric. 10, 525.

Reynolds, T.J., Gutman, J., 1988. Laddering theory, method, analysis, and interpretation. J. Advert. Res. 28, 11-31.

Roccas, S., Sagiv, L., Schwartz, S.H., Knafo, A., 2002. The Big Five personality factors and personal values. Pers. Soc. Psychol. Bull. 28, 789-801.

Rohan, M.J., 2000. A rose by any name? The values construct. Pers. Soc. Psychol. Rev. 4, 255-277.

Schwartz, S.H., 1992. Universals in the content and structure of values: theoretical advances and empirical tests in 20 countries. Adv. Exp. Soc. Psychol. 1-65.

Schwartz, S.H., 2012. An overview of the Schwartz theory of basic values. Online Readings in Psychology and Culture 2, 1-20.

Schwartz, S.H., Boehnke, K., 2004. Evaluating the structure of human values with confirmatory factor analysis. J. Res. Pers. 38, 230-255.

Sok, J., Fischer, E.A.J., 2019. Farmers' heterogeneous motives, voluntary vaccination and disease spread: an agent-based model. Eur. Rev. Agric. Econ. 47, 1201-1222. 
Sok, J., van der Lans, I.A., Hogeveen, H., Elbers, A.R.W., Oude Lansink, A.G.J.M., 2018. Farmers' preferences for bluetongue vaccination scheme Attributes: an integrated choice and latent variable approach. J. Agric. Econ. 69, 537-560.

Sörbom, D., 1989. Model modification. Psychometrika 54, 371-384.

Statistics Sweden, Swedish Board of Agriculture, 2017. Jordbruksstatistisk

Sammanställning 2017 - Med Data Om Livsmedel - Tabeller, Sveriges officiella Statistik. Swedish Board of Agriculture and Statistics Sweden.

Swedish Government, 2017. In: Government, S. (Ed.), Regeringens Proposition 2016/17 104 En Livsmedelsstrategi För Sverige - Fler Jobb Och Hållbar Tillväxt I Hela Landet.

Swedish University of Agricultural Sciences, 2018. Rapport Om Uppdraget Att, Inom Ramen För Livsmedelsstrategin, Analysera Effekter Av Jordförvärvs- Och Arrendelagstiftningen (N2017/04215/JM). Swedish University of Agricultural Sciences.

van Geenhuizen, M., Soetanto, D.P., 2009. Academic spin-offs at different ages: a case study in search of key obstacles to growth. Technovation 29, 671-681.
Viaggi, D., Raggi, M., Paloma, S.G.y., 2011. Understanding the determinants of investment reactions to decoupling of the Common Agricultural Policy. Land Use Pol. 28, 495-505.

Vrain, E., Lovett, A., 2016. The roles of farm advisors in the uptake of measures for the mitigation of diffuse water pollution. Land Use Pol. 54, 413-422.

Walker, J., Ben-Akiva, M., 2002. Generalized random utility model. Math. Soc. Sci. 43, 303-343.

Willock, J., Deary, I.J., McGregor, M.M., Sutherland, A., Edwards-Jones, G., Morgan, O., Dent, B., Grieve, R., Gibson, G., Austin, E., 1999. Farmers' attitudes, objectives, behaviors, and personality traits: the Edinburgh study of decision making on farms. J. Vocat. Behav. 54, 5-36.

Winklhofer, H.M., Diamantopoulos, A., 2002. Managerial evaluation of sales forecasting effectiveness: a MIMIC modeling approach. Int. J. Res. Market. 19, 151-166.

Zhao, H., Seibert, S.E., 2006. The big five personality dimensions and entrepreneurial status: a meta-analytical review. J. Appl. Psychol. 91, 259-271.

Zhao, H., Seibert, S.E., Lumpkin, G.T., 2010. The relationship of personality to entrepreneurial intentions and performance: a meta-analytic review. J. Manag. 36, 381-404. 